\title{
Density determination of focused-electron-beam-induced deposits with simple cantilever-based method
}

\author{
I. Utke, ${ }^{\text {a) }}$ V. Friedli, and J. Michler \\ Nanomechanics and Nanopatterning Group, EMPA Materials Science and Technology, \\ Feuerwerkerstrasse 39, CH-3602 Thun, Switzerland \\ T. Bret, X. Multone, and P. Hoffmann \\ Advanced Photonics Laboratory, Ecole Polytechnique Fédérale de Lausanne (EPFL), \\ 1015 Lausanne, Switzerland
}

(Received 2 August 2005; accepted 2 November 2005; published online 18 January 2006)

\begin{abstract}
Freestanding deposits are grown on a silicon cantilever from a precursor gas by an electron induced process. Deposit mass determination is performed with an atomic force microscopy setup, where the cantilever resonance frequency shift, resulting from mechanical removal of the deposit, is measured. Deposits from hexafluoroacetylacetonato- $\mathrm{Cu}(\mathrm{I})$-vinyltrimethylsilane show densities ranging from $2.05 \pm 0.45$ to $3.75 \pm 0.55 \mathrm{~g} / \mathrm{cm}^{3}$. Deposits from tetramethoxysilane have a constant density of $(1.9 \pm 0.3) \mathrm{g} / \mathrm{cm}^{3}$. Densities of deposits from $\mathrm{Co}_{2}(\mathrm{CO})_{8}$ and $\left[\mathrm{RhCl}\left(\mathrm{PF}_{3}\right)_{2}\right]_{2}$ are linearly related to their composition. The ratio of impinging electrons per deposited atom, beam heating, and thermal stability of the precursor molecule determine the density and composition in focused-electron-beam-induced deposits. (C) 2006 American Institute of Physics.

[DOI: 10.1063/1.2158516]
\end{abstract}

For several decades local three-dimensional deposition with focused ion beams (FIBs) and focused electron beams (FEBs) have been established as methods for prototype nanofabrication due to their inherent flexibility in shape and material. The density of FIB-grown, submicron-diameter pillars from phenanthrene $\left(\mathrm{C}_{10} \mathrm{H}_{14}\right)$ and tungsten hexacarbonyl $\left[\mathrm{W}(\mathrm{CO})_{6}\right]$ precursor was determined ${ }^{1-3}$ as a function of the precursor flux. A quartz crystal microbalance setup has been reported: FIB induced deposition with the precursor dimethyl-gold-hexafluoro-acetylacetonate $\mathrm{Me}_{2} \mathrm{Au}(\mathrm{hfac})$ resulted in approximately $10 \mathrm{~g} / \mathrm{cm}^{3}$ dense films. ${ }^{4}$ Recently, zeptogram mass resolution was reported for contamination deposition. $^{5}$

In this letter we report on a simple method of density measurement involving the mechanical removal of a freestanding deposit from a cantilever. The advantage is that the cantilever's force constant needs not to be estimated or calibrated as in previous investigations, ${ }^{1-3,5}$ and that artifacts due to co-deposits are avoided.

Commercially available $\mathrm{Si}$ cantilevers (NANOSENSORS, type PPP-NCH, length $129 \mu \mathrm{m}$, mean width $32 \mu \mathrm{m}$, and thickness $3.63 \mu \mathrm{m}$ ) were used as the substrate. A microtube, centered to the electron beam, supplies the precursor from an internal metal reservoir. Precursor filling was accomplished within a glovebox under dry $\mathrm{N}_{2}$ atmosphere. In our study we used the precursors (hfac)CuVTMS (hexafluoroacetylacetonato- $\mathrm{Cu}(\mathrm{I})$-vinyltrimethylsilane: $\mathrm{C}_{5} \mathrm{O}_{2}$ $\mathrm{HF}_{6}-\mathrm{Cu}(\mathrm{I})-\mathrm{C}_{5} \mathrm{H}_{12} \mathrm{Si}$, CAS: 139566-53-3), TMOS (tetramethyl-orthosilicate: $\mathrm{Si}\left(\mathrm{OCH}_{3}\right)_{4}$, CAS: 681-84-5), $\mathrm{Co}_{2}(\mathrm{CO})_{8}$ (dicobalt-octacarbonyl, CAS: 10210-68-1), and di- $\mu$-chloro-tetrakis(trifluorophosphine)-dirhodium $\left.\left[\mathrm{RhCl}\left(\mathrm{PF}_{3}\right)_{2}\right]_{2}, \mathrm{CAS}: 14876-98-3\right)$. The corresponding precursor flux values at the nozzle exit were $1 \times 10^{18}, 6 \times 10^{20}$, $9 \cdot 10^{17}$, and $3 \cdot 10^{17}$ molecules $/ \mathrm{cm}^{2} \mathrm{~s}$. FEB exposure was performed with $25 \mathrm{keV}$ electrons in a Cambridge S100 scanning

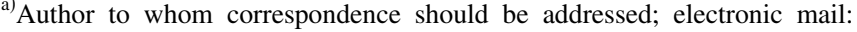
ivo.utke@empa.ch
}

electron microscope (SEM) equipped with a Nabity lithography system and an oil-free turbo pump system. At the background pressure of $10^{-6}$ mbar no deposition was observed.

Figure 1 schematically shows the setup. The cantilever was placed vertically and the SEM operated in spot mode. The beam current was varied between $100 \mathrm{pA}$ to $1 \mathrm{nA}$. After exposure, the sample was transferred to a SEM (Philips XL-30 FEG) for geometry determination and energy dispersive $\mathrm{x}$-ray spectroscopy (EDXS) at $8 \mathrm{kV}$. Resonance frequency shift measurements were performed in an atomic force microscope (AFM DI 4) using the positioning micrometer screws and a sharp substrate edge for "in situ" deposit removal. The essential advantage is that the deposited mass, deduced from the resonance frequency shift, is unambiguously related to the removed deposit volume. Any codeposited material due to scattered electrons does not enter into the measurement. The removed volumes as well as precise cantilever dimensions were determined by SEM observation.

The removed deposit mass $m_{\text {dep }}$ can be calculated from the ratio of the resonance frequencies:

$$
m_{\text {dep }}=\left(m_{\text {eff }}+m_{\text {pyr }}\right)\left(f_{\text {cant }}^{2} / f_{\text {cant }+ \text { dep }}^{2}-1\right)
$$

with $f_{\text {cant+dep }}$ and $f_{\text {cant }}$ the first resonance frequencies of the cantilever before and after removing the deposit mass, respectively, and $m_{\text {eff }}=m_{\text {cant }} \cdot 33 / 140$ the effective cantilever mass. ${ }^{6}$ Eq. (1) assumes that the deposit and the pyramid are placed at the very end of the cantilever. The mass of the cantilever $m_{\text {cant }}$ and the pyramid $m_{\mathrm{pyr}}$ are given by their volumes and the density of $\mathrm{Si}, 2.33 \mathrm{~g} / \mathrm{cm}^{3}$. The force constant of the cantilever cancels out in Eq. (1), since it does not change during the mechanical removal of the deposited tip. A precision of about $\pm 14 \%$ is obtained for the density of the deposit.

Tip masses versus tip volumes are plotted in Fig. 2 for deposits grown from (hfac)CuVTMS at different electron beam currents. Minimum and maximum density values of the $500 \mathrm{pA}$ and $1 \mathrm{nA}$ deposits vary within $(3.2 \ldots 4.3) \mathrm{g} / \mathrm{cm}^{3}$, 


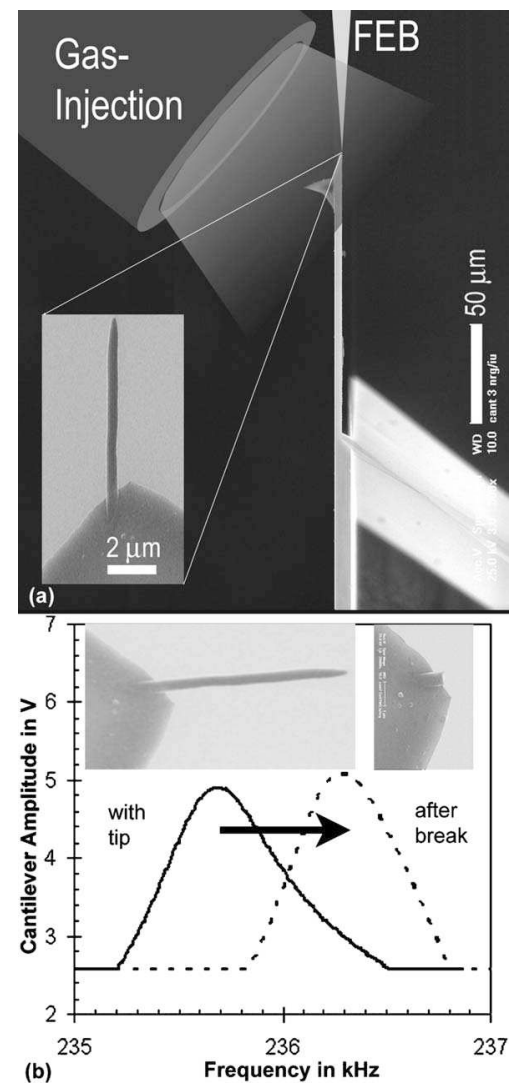

FIG. 1. Principle of density determination of FEB deposits. (a) FEB-induced tip deposition on an AFM cantilever with injected precursor gas (not at scale). (b) Resonance frequency measured before and after removing the tip deposit in an AFM setup. The insets show corresponding SEM images needed to determine the removed tip volume.

whereas the values of the $100 \mathrm{pA}$ deposits vary within $(1.6 \ldots 2.5) \mathrm{g} / \mathrm{cm}^{3}$. These variations are due to variations in the electron flux and precursor coverage. The adsorbed amount of precursor per area decreases exponentially with increasing temperature due to increasing desorption. ${ }^{7}$ The temperature increase at the tip apex can be calculated as follows: Deposited tips had diameters $D \approx 600 \mathrm{~nm}$ and variable tip lengths $L=5-8 \mu \mathrm{m}$. The energy loss per electron is $E=w \cdot \Delta E / \Delta s=2.2 \mathrm{keV}$, with $w=800 \mathrm{~nm}$ the average path length of primary electrons inside the apex according to Monte Carlo simulations and $\Delta E / \Delta s=2.75 \mathrm{eV} / \mathrm{nm}$ (for a $\mathrm{Cu}_{0.2} \mathrm{C}_{0.8}$ deposit) the Bethe stopping power. At $1 \mathrm{nA}$ beam current the power $P=2.2 \times 10^{-6} \mathrm{~W}$ must be dissipated from the tip apex. In equilibrium $\Delta T=4 P L /\left(\pi \kappa D^{2}\right)^{8}=62 \mathrm{~K}$ for a tip with $8 \mu \mathrm{m}$ length. The thermal conductance $\kappa$ is set to $1 \mathrm{~W} / \mathrm{mK}$, which is within the range reported for amorphous carbon $0.2-2.2 \mathrm{~W} / \mathrm{mK}^{9}$ and vitreous $\mathrm{SiO}_{2} 1.35 \mathrm{~W} / \mathrm{mK} .{ }^{10}$ The resulting apex temperature of $87^{\circ} \mathrm{C}$ is close to the temperature of thermal dissociation of (hfac)CuVTMS being at $63{ }^{\circ} \mathrm{C}^{11}$ and $\mathrm{Co}_{2}(\mathrm{CO})_{8}$ being at around $100{ }^{\circ} \mathrm{C}^{12}$ For such long tips, the composition along the tip axis was not uniform and an average composition value was taken.

The ratio of impinging electrons to deposited atoms comprises any variations of precursor coverage via the measured deposited mass

$$
\frac{\text { electrons }}{\text { deposited_atoms }}=\frac{I_{P} t / e}{m_{\text {dep }} N_{A} / M_{\text {dep }}}
$$

with $M_{\text {dep }}$ the molar mass of the deposit, $I_{p}$ the beam current, $t$ the deposition time, $N_{A}$ Avogadro's constant, and $e$ the elec-

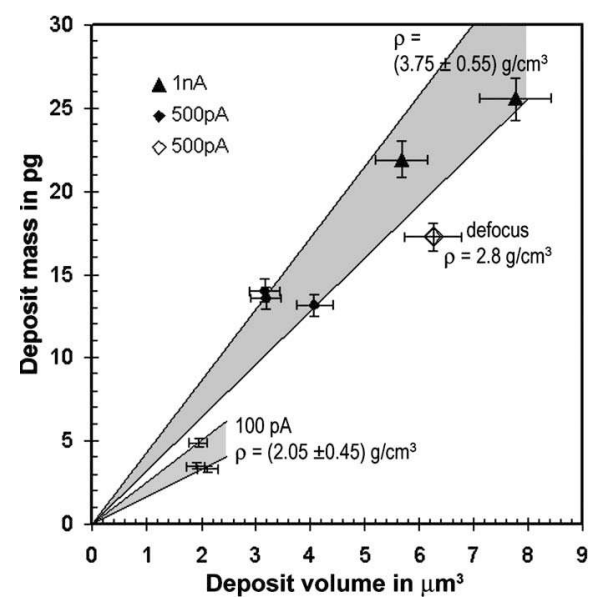

FIG. 2. Mass-versus-volume plot of tip deposits grown with (hfac)CuVTMS at $25 \mathrm{kV}$ and beam currents varying from $100 \mathrm{pA}$ to $1 \mathrm{nA}$. The defocus exposure at $500 \mathrm{pA}$ results in low density.

tron charge. The molar mass is calculated from the measured composition of the deposit. In Fig. 3 the compositions are given in generalized form. For deposits from (hfac)CuVTMS the composition is $\mathrm{Cu}_{x} \mathrm{M}_{1-x}$, where $M$ contains all the matrix elements arising from the precursor ligands: C, F, O, and Si. For deposits from TMOS the silicon is assumed to exist as oxide $\mathrm{SiO}_{2}$, hence the generalized composition is written as $\left(\mathrm{SiO}_{2}\right)_{x} \mathrm{M}_{1-x}$, where $M$ contains carbon and oxygen. Since EDXS is insensitive to hydrogen it is not included in any of the given composition values. From infrared spectroscopy of organic FEB deposits the hydrogen content can be estimated to be about 2-3 times the oxygen content, ${ }^{13}$ thus negligibly affecting the $M_{\text {dep }}$ value.

Deposit density and composition are both related through the process of precursor molecule dissociation by electron irradiation. The precursor stoichiometries $\mathrm{Cu}_{0.05} \mathrm{M}_{0.95} \quad$ [for (hfac)CuVTMS] and $\left(\mathrm{SiO}_{2}\right)_{0.14} \mathrm{M}_{0.86}$ (for TMOS) change to deposit compositions $\mathrm{Cu}_{x} \mathrm{M}_{1-x}$ $(x=0.16 \ldots 0.3)$ and $\left(\mathrm{SiO}_{2}\right)_{0.33} M_{0.67}$ by partly decomposing the precursor matrix and thus rising the copper or $\mathrm{SiO}_{2}$ content of the deposit, respectively. In parallel, an increase from precursor density $1.37 \mathrm{~g} / \mathrm{cm}^{3}$ for (hfac)CuVTMS ${ }^{14}$ and $1.023 \mathrm{~g} / \mathrm{cm}^{3}$ for TMOS ${ }^{15}$ to the respective deposit density $(1.6 \ldots 4.3) \mathrm{g} / \mathrm{cm}^{3}$ and $(1.9 \pm 0.3) \mathrm{g} / \mathrm{cm}^{3}$ is observed, see Fig. 3. Matrix decomposition for TMOS is relatively constant within $10 \ldots 20$ electrons/(deposited atom) and the deposit

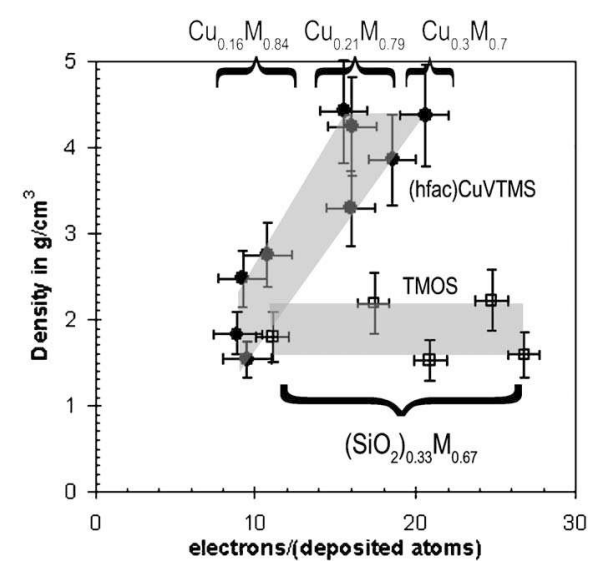

FIG. 3. Deposit density plotted versus number of electrons per deposited atom, see Eq. (2). Deposit compositions are given in generalized form,

where $M$ stands for the cabonaceous matrix.
to AIP license or copyright, see http://apl.aip.org/apl/copyright.jsp 
TABLE I. Density calculations for the carbonaceous matrix in deposits from TMOS and (hfac)CuVTMS. Densities are taken as: $\mathrm{Cu} 8.96 \mathrm{~g} / \mathrm{cm}^{3}$, and $\mathrm{SiO}_{2} 2.2 \mathrm{~g} / \mathrm{cm}^{3}$. Deposit densities and compositions are measured values.

\begin{tabular}{ccccc}
\hline \hline & $\begin{array}{c}\text { Electrons/ } \\
\text { (deposited } \\
\text { atom) }\end{array}$ & $\begin{array}{c}\text { Deposit } \\
\text { composition }\end{array}$ & $\begin{array}{c}\text { Deposit } \\
\text { density in } \\
\mathrm{g} / \mathrm{cm}^{3}\end{array}$ & $\begin{array}{c}\text { Matrix } \\
\text { density in } \\
\mathrm{g} / \mathrm{cm}^{3}\end{array}$ \\
\hline TMOS & $11-27$ & $\left(\mathrm{SiO}_{2}\right)_{0.33}$ Matrix $_{0.67}$ & $1.87 \pm 0.33$ & $1.75 \pm 0.45$ \\
(hfac)CuVTMS & $9-11$ & $\mathrm{Cu}_{0.14}$ Matrix $_{0.86}$ & $2.05 \pm 0.45$ & $0.94 \pm 0.52$ \\
(hfac)CuVTMS & $15-18$ & $\mathrm{Cu}_{0.2}$ Matrix $_{0.8}$ & $3.75 \pm 0.55$ & $2.45 \pm 0.65$ \\
& $21-22$ & $\mathrm{Cu}_{0.3}$ Matrix $_{0.7}$ & $4.3 \pm 0.58$ & $2.3 \pm 0.8$ \\
\hline \hline
\end{tabular}

density is somewhat lower than that of $\mathrm{SiO}_{2} 2.2 \mathrm{~g} / \mathrm{cm}^{3}$. Calculating the matrix density with $\rho_{\text {Matrix }}=\left(\rho_{\text {Deposit }}\right.$ $\left.-x \cdot \rho_{\mathrm{SiO}_{2}}\right) /(1-x)$ gives a value of $(1.75 \pm 0.45) \mathrm{g} / \mathrm{cm}^{3}$ reported in Table I. This is in the range of published densities around $2 \mathrm{~g} / \mathrm{cm}^{3}$ of FIB deposits from phenanthrene. ${ }^{2}$ With respect to the above estimated apex temperature of about $90{ }^{\circ} \mathrm{C}$, this molecule is thermally stable (dissociation temperature at around $\left.580{ }^{\circ} \mathrm{C}\right) .{ }^{16}$ The changes in density and composition can be attributed to irradiative decomposition at $25 \mathrm{keV}$. In contrast, deposits from the metalorganic precursor (hfac)CuVTMS show a strong correlation of matrix decomposition and content with electrons/(deposited atom) since the dissociation temperature of the VTMS ligand is at $63^{\circ} \mathrm{C},{ }^{11}$ i.e., within our temperature estimation. Increasing the beam current induces two parallel effects: (a) more electrons are available for irradiative matrix decomposition and (b) the tip apex becomes hotter and leads to thermal dissociation of the molecule. Both contributions lead to enhanced metal content and density of the deposit as shown in Fig. 3. The corresponding matrix densities $\rho_{\text {Matrix }}=\left(\rho_{\text {Deposit }}\right.$ $\left.-x \cdot \rho_{\mathrm{Cu}}\right) /(1-x)$ were calculated in Table I. At low number of electrons per deposited atom (100 pA current $)$ the thermal contribution is negligible. The deposit composition of about 14 at. $\% \mathrm{Cu}$ and the matrix density of $(0.94 \pm 0.52) \mathrm{g} / \mathrm{cm}^{3}$ being comparable to hydrogen-rich amorphous carbon $^{17}$ can be attributed to irradiative decomposition. A comparatively dense matrix with $(2.45 \pm 0.65) \mathrm{g} / \mathrm{cm}^{3}$ is obtained for the $(0.5-1) \mathrm{nA}$ deposits at around 14 electrons/(deposited atoms). This compares well to the maximum density of $2.4 \mathrm{~g} / \mathrm{cm}^{3}$ of a highly crosslinked, weakly hydrogenated amorphous $\mathrm{C}$ network ${ }^{17}$ and might be attributed to the inset of thermal dissociation which also leads to the increased copper content of 21 at. \%. At around 23 electrons per deposited atoms a tip with $9 \mu \mathrm{m}$ length and average 30 at. \% $\mathrm{Cu}$ was obtained. This tip shows increasing $\mathrm{Cu}$ content along its axis and a rough surface which is attributed to thermal precursor dissociation and subsequent ligand evaporation.

The precursors $\mathrm{Co}_{2}(\mathrm{CO})_{8}$ and $\left[\mathrm{RhCl}\left(\mathrm{PF}_{3}\right)_{2}\right]_{2}$ do not contain hydrogen. According to EDXS compositions in Table II, matrices with low content of volatile elements are formed under electron irradiation. When calculating the compositional deposit density from the atomic ratio of the composing nonvolatile elements (Co:C and $\mathrm{Rh}: \mathrm{P})$, an agreement of better than $10 \%$ with measurements is found. Since the volatile matrix elements were neglected, a slight overestimation results. The large Co content and the high deposit density of
TABLE II. Comparison of measured and compositional densities of deposits from $\mathrm{Co}_{2}(\mathrm{CO})_{8}$ and $\left[\mathrm{RhCl}\left(\mathrm{PF}_{3}\right)_{2}\right]_{2}$. Densities are taken as: $\mathrm{Co} 8.9 \mathrm{~g} / \mathrm{cm}^{3}$, carbon $(a-\mathrm{C}: \mathrm{H}): 1.5 \mathrm{~g} / \mathrm{cm}^{3}, \mathrm{P} 1.8 \mathrm{~g} / \mathrm{cm}^{3}, \mathrm{Rh} 12.4 \mathrm{~g} / \mathrm{cm}^{3}$. The compositional density $\rho$ of $A_{x} B_{1-x}$ is calculated according to $\rho=x \cdot \rho_{A}+(1-x) \cdot \rho_{B}$.

\begin{tabular}{ccccc}
\hline \hline Precursor & $\begin{array}{c}\text { Beam } \\
\text { current }\end{array}$ & $\begin{array}{c}\text { Deposit } \\
\text { composition }\end{array}$ & $\begin{array}{c}\text { Measured } \\
\text { density in } \\
\mathrm{g} / \mathrm{cm}^{3}\end{array}$ & $\begin{array}{c}\text { Compositional } \\
\text { density in } \\
\mathrm{g} / \mathrm{cm}^{3}\end{array}$ \\
\hline $\mathrm{Co}_{2}(\mathrm{CO})_{8}$ & $100 \mathrm{nA}$ & $\mathrm{Co}_{0.73} \mathrm{C}_{0.18} \mathrm{O}_{0.09}$ & $7.2 \pm 0.97$ & 7.4 \\
$\mathrm{Co}_{2}(\mathrm{CO})_{8}$ & $100 \mathrm{pA}$ & $\mathrm{Co}_{0.31} \mathrm{C}_{0.54} \mathrm{O}_{0.15}$ & $4.2 \pm 0.57$ & 4.2 \\
{$\left[\mathrm{RhCl}\left(\mathrm{PF}_{3}\right)_{2}\right]_{2}$} & $1 \mathrm{nA}$ & $\mathrm{Rh}_{0.7} \mathrm{P}_{0.25} \mathrm{~F}_{0.05}$ & $8.8 \pm 1.2$ & 9.6 \\
\hline \hline
\end{tabular}

the $100 \mathrm{nA}$ deposit from $\mathrm{Co}_{2}(\mathrm{CO})_{8}$ are due to thermal decomposition by beam heating according to our apex temperature estimation and previous results. ${ }^{12,18}$ Properties of the $100 \mathrm{pA}$ deposit are probably dominated by irradiative decomposition. The $\left[\mathrm{RhCl}\left(\mathrm{PF}_{3}\right)_{2}\right]_{2}$ molecule is thermally more stable (dissociation temperature $150{ }^{\circ} \mathrm{C}$ ) ${ }^{19}$ and the high metal content within the tips can be attributed to irradiative dissociation.

In conclusion, a cantilever-based density measurement setup with subpicogram mass resolution is presented. It avoids any artifacts from parasitic co-deposition. Two coupled decomposition mechanisms affect the deposit composition and density: irradiative decomposition causing bond breaking and matrix reticulation and thermal dissociation mainly increasing the deposit metal content. The role of both mechanisms will be further studied with a piezo-resistive cantilever setup allowing for mass detection during FEBinduced deposition.

Dr. P. Doppelt is acknowledged for synthesis of the $\left[\mathrm{RhCl}\left(\mathrm{PF}_{3}\right)_{2}\right]_{2}$ precursor. The CTI/Top Nano 21 program and the SNF (No. 21-64064.00) are acknowledged for funding.

${ }^{1}$ M. Ishida, J. Fujita, T. Ichihashi, Y. Ochiai, T. Kaito, and S. Matsui, J. Vac. Sci. Technol. B 21, 2728 (2003).

${ }^{2}$ M. Ishida, J. Fujita, and Y. Ochiai, J. Vac. Sci. Technol. B 20, 2784 (2002).

${ }^{3}$ J. Fujita, M. Ishida, T. Ichihashi, Y. Ochiai, T. Kaito, and S. Matsui, Nucl. Instrum. Methods Phys. Res. B 206, 472 (2003).

${ }^{4}$ A. D. Dubner and A. Wagner, J. Appl. Phys. 65, 3636 (1989).

${ }^{5}$ M. Nishio, S. Sawaya, S. Akita, and Y. Nakayama, Appl. Phys. Lett. 86, 133111 (2005).

${ }^{6}$ W. Weaver, S. P. Timoshenko, and D. H. Young, Vibration Problems in Engineering (Wiley, New York, 1990).

${ }^{7}$ R. W. Christy, J. Appl. Phys. 31, 1680 (1960).

${ }^{8}$ L. Reimer, Scanning Electron Microscopy (Springer, Berlin, 1998).

${ }^{9}$ A. J. Bullen, K. E. O'Hara, D. G. Cahill, O. Monteiro, and A. von Keudell, J. Appl. Phys. 88, 6317 (2000).

${ }^{10}$ D. R. Lide, Handbook of Chemistry and Physics (CRC, New York, 1997).

${ }^{11}$ K.-K. Choi and S.-W. Rhee, Thin Solid Films 409, 147 (2002).

${ }^{12}$ I. Utke, J. Michler, P. Gasser, C. Santschi, D. Laub, M. Cantoni, P. A. Buffat, C. Jiao, and P. Hoffmann, Adv. Eng. Mater. 7, 323 (2005).

${ }^{13}$ T. Bret, S. Mauron, I. Utke, and P. Hoffmann, Microelectron. Eng. 78-79, 300 (2005)

${ }^{14}$ Schumacher product note Cupraselect.

${ }^{15} \mathrm{http}: / /$ chemfinder.cambridgesoft.com

${ }^{16}$ J. C. S. Chu, R. Soller, M. C. Lin, and C. F. Melius, J. Phys. Chem. 99, 663 (1995)

${ }^{17}$ J. Robertson, Mater. Sci. Eng., R. 37, 129 (2002).

${ }^{18}$ I. Utke, T. Bret, D. Laub, P. Buffat, L. Scandella, and P. Hoffmann, Microelectron. Eng. 73-74, 553 (2004).

${ }^{19}$ P. Doppelt, V. Weigel, and P. Guinot, Mater. Sci. Eng., B 17, 143 (1993). 